\title{
PENYULUHAN KESEHATAN TENTANG KARIES GIGI DAN LOMBA GOSOK GIGI DI WILAYAH RT 08 KELURAHAN MURNI
}

\author{
Mira Andani ${ }^{1}$, Robby Hardian ${ }^{2}$, Win Fadillah ${ }^{3)}$, Vevi Suryenti Putri ${ }^{4)}$, Maimaznah $^{5)}$ \\ ${ }^{1,2,3,4}$ Prodi Profesi Ners, Sekolah Tinggi Ilmu Kesehatan Baiturahim Jambi \\ ${ }^{5}$ Prodi DIII Keperawatan, Sekolah Tinggi Ilmu Kesehatan Baiturahim Jambi \\ Email.miraandani07@gmail.com
}

\begin{abstract}
Damage of teeth can be affect for health of the other body, so it will interfere with daily activities. Based of the assessment in 26 school-age children in RT 08 Kelurahan Murni, showed 20 people (76.92\%) who had tooth holes and black teeth, even though 18 people (69.23\%) had brushed their teeth twice a day. Therefore, it is necessary to conduct health education on dental caries and tooth brushing competitions accompanied by demonstrations so that children can find out how to brush their teeth properly to avoid dental caries. The target of this counseling is that school-age children can practice the correct way of brushing their teeth to prevent dental caries. Extension activities were carried out for 45 minutes with the stages of directing participants to the place to be counseled, opening the presentation delivered by the moderator, delivering counseling material delivered by the presenter, demonstrating how to brush teeth properly, directing children to take part in brushing competitions, conducting competitions brush your teeth, give gifts to children who can brush their teeth properly, evaluate the counseling participants, distribute leaflets to the audience, document activities. The results of counseling activities are children are able to do the right way to brush their teeth.
\end{abstract}

Keywords: brushing teet, dental caries, school age, children

\begin{abstract}
ABSTRAK
Kerusakan pada gigi dapat mempengaruhi kesehatan anggota tubuh lainnya, sehingga akan mengganggu aktivitas sehari-hari. Berdasarkan data pengkajian, pada 26 anak usia sekolah di wilayah RT 08 Kelurahan Murni menunjukkan 20 orang (76,92\%) kondisi gigi anak usia sekolah berlubang dan hitam, meskipun 18 orang $(69,23 \%)$ anak sudah menggosok gigi 2 kali dalam sehari. Oleh karena itu perlu diadakan penyuluhan kesehatan tentang karies gigi dan lomba gosok gigi yang disertai dengan demonstrasi agar anak bisa mengetahui bagaimana cara menggosok gigi yang benar agar terhindar dari karies gigi. Adapun target dalam penyuluhan ini adalah anak usia sekolah dapat mempraktekkan cara menggosok gigi yang benar untuk mencegah karies gigi. Kegiatan penyuluhan dilaksanakan selama 45 menit dengan tahapan berupa mengarahkan peserta ke tempat yang akan dilakukan penyuluhan, melakukan pembukaan yang disampaikan oleh moderator, menyampaikan materi penyuluhan yang disampaikan oleh penyaji, mendemonstrasikan cara menggosok gigi yang benar, mengarahkan anak untuk mengikuti lomba gosok gigi, melakukan lomba gosok gigi, memberikan hadiah pada 3 anak yang bisa gosok gigi yang benar, melakukan evaluasi pada peserta penyuluhan, membagikan leaflet pada audiens, mendokumentasikan kegiatan. Hasil dari kegiatan penyuluhan adalah anak mampu melakukan cara menggosok gigi yang benar.
\end{abstract}

Kata Kunci : karies gigi, gosok gigi, anak usia sekolah

\section{PENDAHULUAN}

Gigi merupakan satu kesatuan dengan anggota tubuh kita yang lain. Kerusakan pada gigi dapat mempengaruhi kesehatan anggota tubuh lainnya, sehingga akan mengganggu aktivitas sehari-hari. Salah satu faktor yang dapat merusak gigi adalah makanan dan minuman, yang mana ada 
yang menyehatkan gigi dan ada pula yang merusak gigi. Upaya kesehatan gigi perlu ditinjau dari aspek lingkungan, pengetahuan, pendidikan, kesadaran masyarakat dan penanganan kesehatan gigi termasuk pencegahan dan perawatan. Namun sebagian besar orang mengabaikan kondisi kesehatan gigi secara keseluruhan. Perawatan gigi dianggap tidak terlalu penting, padahal manfaatnya sangat vital dalam menunjang kesehatan dan penampilan (Pratiwi, 2017).

Mulut bukan hanya untuk pintu masuknya makanan dan minuman, tetapi fungsi mulut lebih dari itu dan tidak banyak orang mengetahui. Mulut merupakan bagian yang penting dari tubuh kita dan dapat dikatakan bahwa mulut adalah cermin dari keadaan gigi karena banyak penyakit umum mempunyai gejala-gejala yang dapat dilihat dalam mulut. Pada umumnya keadaan kebersihan mulut anak lebih buruk dan anak lebih banyak makanan dan minuman yang menyebabkan karies dibanding orang dewasa (Machfoedz dan Zein, 2015).

Usia sekolah adalah usia puncak pertumbuhan anak sekolah dasar yang berusia sekitar 7-12 tahun. Usia sekolah merupakan masa-masa pertumbuhan paling pesat kedua setelah masa balita. Kesehatan yang optimal akan menghasilkan pertumbuhan yang optimal pula. Perhatian terhadap kesehatan sangatlah diperlukan, pendidikan juga digalakkan untuk perkembangan mental yang mengacu pada keterampilan anak (Susilowati \& Kuspriyanto, 2016).

Perkembangan kognitif anak akan telihat dari kemampuan untuk berfikir dengan cara yang logis bukan sesuatu yang abstrak. Pada usia 7 tahun anak memasuki tahap yaitu perkembangan konkret. Pada tahap ini kemampuan anak untuk berpikir secara logis semakin berkembang. Hubungan dengan teman sebaya pun sudah terjalin.
Perkembangan psikologis anak usia sekolah di lihat dari perjuangan anak mendapatkan kompetensi dan keterampilan yang penting bagi mereka untuk sejajar dengan orang dewasa (Wong, 2014).

Usia sekolah merupakan masa dimana anak suka jajan makanan sembarangan sesuai dengan yang dia suka seperti gulagula namun motivasi yang dimiliki dalam melakukan perawatan gigi kurang. Apabila anak terlalu banyak makan-makanan manis dan jarang membersihkan segera setelah makan manis tersebut maka akan timbul masalah pada gigi-giginya. Gigi anak akan rusak dan berlubang karena kuman sehingga muncul masalah kesehatan gigi yaitu karies gigi (Machfoedz dan Zein, 2015).

Anak sekolah tidak dapat ditebak selera makan yang disenangi, perubahan sikap terhadap makan dipengaruhi oleh beberapa faktor, salah satunya adalah pengaruh dari luar. Pada masa-masa inilah, perhatian ibu terhadap pengaruh pola konsumsi makanan anak sangat penting agar terhindar dari karies gigi (Susilowati \& Kuspriyanto, 2016).

Karies gigi merupakan penyakit kronis anak-anak yang sering terjadi dan tingkatnya 5 kali lebih tinggi dari asma. Karies merupakan penyebab patologi primer atas penanggalan gigi pada anakanak (Irma \& Intan, 2013). Karies gigi sering terjadi pada anak sekolah karena anak terlalu sering makan cemilan yang lengket dan banyak mengandung gula. Konsistensi makan, seperti sifat lengket, juga menentukan panjang waktu pajan terhadap karbohidrat dengan planque bakteri. Didalam planque inilah bakteri pembentuk asam berkembangbiak sembari meragi karbohidrat. Pada level tertentu, asam yang terbentuk akan menyebabkan perlubangan.

Makanan yang dapat dengan mudah menimbulkan karies, antara lain keripik 
kentang, permen (terurtama permen karet), kue yang berisi krim, kue kering, dan minuman manis. Namun, pada prinsipnya makanan apapun (termasuk buah-buahan) dapat menimbulkan karies bila sesudah makan anak tidak dibiasakan segera menggosok gigi (Arisman, 2011).

Kesehatan gigi dan mulut masyarakat Indonesia masih merupakan hal yang perlu mendapat perhatian serius dari tenaga kesehatan, baik dokter, perawat dan perawat gigi. Menurut data terbaru yang dikeluarkan Departemen Kesehatan dari Riskesdas (2018) mencatat proporsi masalah gigi dan mulut sebesar 57,6\%, yang mendapatkan pelayanan dari tenaga medis gigi sebesar $10,2 \%$ dan perilaku menyikat gigi yang benar sebesar $2,8 \%$. Berdasarkan Riskesdas (2013) persentase penduduk yang mempunyai masalah kesehatan gigi dan mulut sebesar 25,9\% sedangkan untuk Provinsi Jambi menunjukkan indeks karies gigi sebesar $4,6 \%$.

Upaya pemeliharan kesehatan gigi sebaiknya dilakukan sedini mungkin sehingga karies gigi dapat dicegah agar tidak sampai terjadi pada anak-anak (Septianingtias \& Sulistyowati, 2017). Upaya yang dapat dilakukan untuk mencegah terjadinya karies, tentu sudah jelas, ialah menggosok gigi dengan pasta gigi (sebaiknya segera sesudah makan), di samping tidak mengkonsumsi makanan yang lengket atau bergula. Karies yang terjadi pada gigi memang tidak berbahaya, namun kejadian ini biasanya berlanjut sampai anak memasuki usia remaja bahkan sampai dewasa. Gigi yang berlubang akan menyerang gigi permanen sebelum gigi tersebut berhasil menebus gusi (Arisman, 2011).

Pentingnya peran orang tua dalam proses pendidikan anak, dilihat dari bagaimana orang tua menjadi contoh yang baik dengan cara membimbing, mengarahkan, dan memberikan motivasi. Apabila orang tua berperan maka anak akan mengerti dan mengamati kemudian anak dapat meniru apa yang dilakukan atau diajarkan oleh orang tua mereka. Sikap dan perilaku orang tua dalam pemeliharan kesehatan gigi memberi pengaruh yang cukup signifikan terhadap perilaku anak.

Orang tua harus mengetahui cara merawat gigi anaknya tersebut, dan orang tua juga harus mengajari anaknya cara merawat ggi yang baik. Orang tua dapat mengurangi risiko terjadinya karies gigi dengan melakukan cara pencegahan karies dengan berkumur dengan air bersih setelah minum susu maupun makan makanan manis, membiasakan anaknya memeriksakan gigi mereka ke dokter gigi 2 kali dalam 1 tahun dan menggosok gigi untuk menjaga kebersihan gigi dan mulut.

Peranan orang tua hendaknya ditingkatkan dalam mengajarkan anak membiasakan diri untuk menyikat gigi secara teratur guna menghindarkan kerusakan gigi pada anak. Salah satu contoh sederhana dalam pemeliharaan kesehatan gigi anak yaitu selalu mengajarkan anak tentang waktu yang tepat dan cara yang baik utuk menggosok gigi serta selalu mengingatkan anak agar setelah mengkonsumsi makanan manis sebaiknya segera berkumur dengan air. Dengan adanya dasar-dasar ilmu yang didapat dari orang tua, anak dapat mengaplikasikannya dalam kehidupan sehari-hari yang dijalaninya.

Orang tua mempunyai peran yang sangat dominan dalam upaya pencegahan karies gigi, dimana orang tua harus mengetahui cara merawat gigi anak dan orang tua juga harus mengajarkan anaknya cara merawat gigi dengan baik sehingga dapat mencegah terjadi kerusakan pada gigi. Pada anakanak, karies gigi masih sering terjadi akibat kurang kesadaran dan perhatian dari orang tua. Banyak orang tua tidak mengetahui 
bahwa karies gigi menjadi indikator keberhasilan upaya pemeliharaan kesehatan gigi. Maka dari itu, perhatian orang tua berperan penting terhadap kesehatan gigi pada anak, terutama anak-anak yang masih balita maupun usia dini.

Berdasarkan hasil penelitian Widyanto (2014) menunjukkan bahwa sebagian besar anak mengalami karies gigi yang disebabkan karena peran orang tua yang kurang. Untuk itu, Peran orang tua sangat dibutuhkan untuk mencegah terjadinya karies gigi pada anak. Peran orang tua juga sangat penting terhadap derajat kesehatan gigi terutama untuk karies gigi, maka dari itu diperlukan pendekatan khusus dalam bentuk perilaku positif.

Berdasarkan data yang didapatkan dari hasil pengkajian yang dilakukan oleh kelompok Rufaidah, pada 26 orang anak sekolah di wilayah RT.08 Kel. Murni menunjukkan 20 orang $(76,92 \%)$ anak usia sekolah berdasarkan kondisi gigi anak saat ini adalah berlubang dan hitam, meskipun 18 orang $(69,23 \%)$ anak sudah menggosok gigi 2 kali dalam sehari, tetapi masih banyak ditemukan gigi anak yang berlubang dan hitam. Hal ini dikarenakan anak usia sekolah tidak mengetahui bagaimana cara menggosok gigi yang benar, sehingga walaupun sudah menggosok gigi 2 kali dalam sehari anak tetap terkena caries gigi. Oleh karena itu perlu diadakan penyuluhan kesehatan tentang karies gigi dan lomba gosok gigi yang disertai dengan demonstrasi agar ibu dan anak bisa mengetahui bagaimana cara menggosok gigi yang benar untuk terhindar dari karies gigi serta ibu dapat mengingatkan anak untuk selalu memelhara kesehatan mulut dan gigi di rumah setelah dilakukan kegiatan ini.

\section{TARGET DAN LUARAN}

Adapun target luaran dalam penyuluhan ini adalah Anak sekolah dapat mengenal dan memahami tentang karies gigi. Anak sekolah dapat mengaplikasikan cara menggosok gigi yang benar dalam kehidupan sehari-hari.

Rencana tindak lanjut dari kegiatan penyuluhan tentang karies gigi adalah berkoordinasi dengan pihak puskesmas program Usaha Kesehatan Gigi Sekolah (UKGS) untuk melakukan penyuluhan tentang karies gigi dengan melibatkan kader di kelurahan murni yang dilaksanakan di sekolah-sekolah dengan jadwal 3 bulan sekali.

\section{METODE PELAKSANAAN}

Pelaksanaan kegiatan penyuluhan akan dilaksanakan selama 45 menit dengan tahapan berupa:

1. Mengarahkan peserta ke tempat yang akan dilakukan penyuluhan

2. Melakukan pembukaan yang disampaikan oleh moderator

3. Menyampaikan materi penyuluhan yang disampaikan oleh penyaji

4. Mendemonstrasikan cara menggosok gigi yang benar

5. Mengarahkan anak untuk mengikuti lomba gosok gigi

6. Melakukan lomba gosok gigi

7. Memberikan hadiah pada 3 anak yang bisa gosok gigi yang benar

8. Melakukan evaluasi pada peserta penyuluhan

9. Membagikan leaflet pada audiens

10. Mendokumentasikan kegiatan

\section{HASIL PEMBAHASAN}

Karies gigi adalah kerusakan jaringan keras gigi yang disebabkan oleh asam yang ada dalam karbohidrat melalui perantara mikroorganisme yang ada dalam saliva (Irma \& Intan, 2013).

Karies merupakan penyebab patologi primer atas penanggalan gigi pada anakanak (Irma \& Intan, 2013). Karies gigi 
sering terjadi pada anak sekolah karena anak terlalu sering makan cemilan yang lengket dan banyak mengandung gula.

Pada prinsipnya makanan apapun (termasuk buah-buahan) dapat menimbulkan karies bila sesudah makan anak tidak dibiasakan segera menggosok gigi (Arisman, 2011).

Karies gigi disebabkan oleh 3 faktor/komponen yang saling beinteraksi, yaitu komponen dari gigi dan air ludah (saliva) yang meliputi: komposisi gigi, posisi gigi, ph saliva, kekentalan saliva, komponen mikroorganisme yang ada dalam mulut yang mampu menghasilkan asam melalui peragian yaitu: Streptococcus, laktobasil, komponen makanan yang mengandung karbohidrat misalnya sukrosa dan glukosa yang dapat diragikan oleh bakteri tertentu dan membentuk asam (Irma \& Intan, 2013).

Sedangkan menurut (Arisman, 2011) faktor penyebab karies gigi adalah host (Gigi), bakteri, substrat atau makanan, waktu. Menurut Sripgupta (2011) tanda dan gejala karies gigi sebagai berikut terdapat bintik berwarna coklat kekuning-kuningan pada gigi yang tidak dibersihkan setelah penyikatan, gigi yang sensitif dengan minuman dingin atau panas, gigi terasa sakit.

Sedangkan menurut Pratiwi (2017) tanda dan gejala munculnya karies gigi adalah tanda awal adalah lesi berbecak putih pada permukaan gigi, sebuah lesi yang muncul cokelat dan mengkilap menunjukkan karies pernah hadir tapi proses demineralisasi telah berhenti, meninggalkan noda, sebuah bercak cokelat yang kusam dalam penampilan mungkin tanda karies aktif, sakit gigi serta linu pada gigi yang berlubang apabila gigi tersebut terkena rangsangan dingin, panas, makanan asin dan manis. Rasa sakit tersebut akan menghilang sekitar 1 sampai 2 detik setelah rangsangan dihilangkan, bau mulut.
Cara pencegahan karies gigi anak dapat dilakukan, diantaranya ajarkan anak untuk membiasakan gosok gigi, baik setelah makan maupun sebelum tidur, bersihkan permukaan gigi dari plak yang menempel agar sisa-sisa makanan terangkat, kurangi mengkonsumsi yang manis-manis, seperti buah, permen, dan cokelat, rajin berkumur setelah makan atau minum sesuatu terutama setelah minum yang manis, hindari konsumsi soda atau minuman sejenis, periksakan kesehatan gigi dengan teratur untuk mencegah munculnya karies gigi pada anak (Susilowati \& Kuspriyanto, 2016).

Cara menggosok gigi yang benar, posisikan sikat gigi pada sudut $45^{\circ}$ dari gusi, maju dan mundur secara lembut dengan gerakan pendek, gunakan ujung sikat untuk membersihkan permukaan dalam gigi depan dengan gerakan keatas dan bawah, sikat lidah dengan lembut untuk menghilangkan bakteri dan menjaga tetap segar.

Menurut penelitian Andhini (2014) tentang "Penyuluhan Kesehatan Tentang Karies Gigi Dan Lomba Gosok Gigi Di Wilayah Rt 08 Kelurahan Murni" menunjukkan bahwa kejadian karies gigi anak, keadaan diperburuk dengan tingkat pengetahuan anak dalam menggosok gigi yang kurang sebanyak (59\%), sikap anak dalam menggosok gigi yang tidak mendukung (61\%), tindakan anak dalam menggosok gigi yang tidak baik $(55 \%)$. Hasil uji X2 menunjukkan bahwa ada hubungan yang bermakna antara perilaku menggosok gigi pada anak dengan kejadian karies gigi, $(\mathrm{p}<0,05)$.

Pelaksanaan penyuluhan telah sesuai dengan yang direncanakan yaitu Kamis, 27 Juni 2019 di Kediaman Ketua RT 08 Kelurahan Murni, namun waktu pelaksanaan tidak sesuai dengan yang direncanakan yang semula pada pukul 14.00 WIB, namun pelaksanaan kegiatan 
dimulai pada pukul 14.25 WIB dikarenakan belum hadirnya ibu-ibu dari anak yang datang menghadiri acara disebabkan banyak kegiatan rumah yang tidak bisa ditinggalkan.

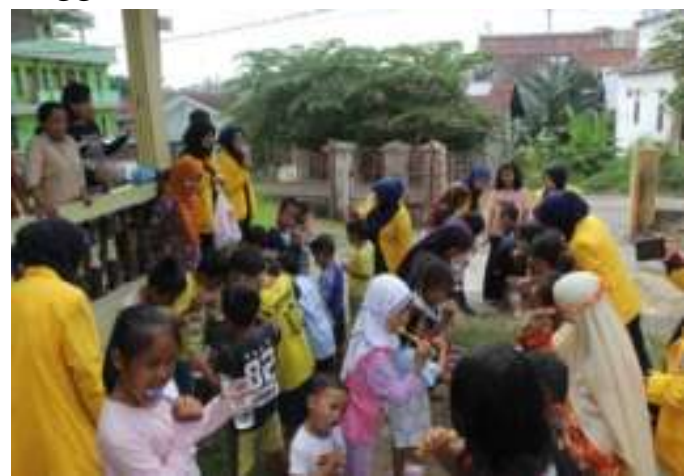

Gambar 1. Kegiatan penyuluhan

Sasaran penyuluhan dilakukan kepada ibu dan seluruh anak sekolah dasar di RT 08 Kel. Murni tetapi juga ada anak usia sekolah yang hadir dalam penyuluhan dari RT.12. Anak sekolah yang datang berjumlah 39 orang serta 7 orang ibu yang datang saat acara penyuluhan.

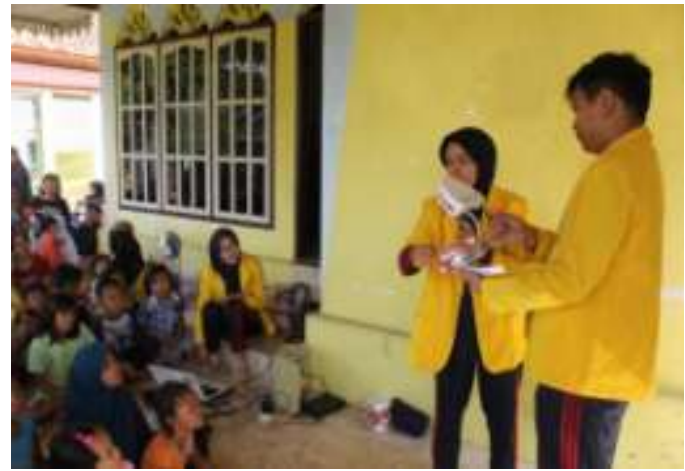

Gambar 2. Kegiatan penyuluhan

Sebelum acara dimulai anak- anak mengisi absensi, acara selanjutnya membuka penyuluhan dengan sambutan oleh moderator, dan membuat kontrak waktu dengan peserta penyuluhan. Setelah itu penyaji menanyakan mengenai gigi berlubang kepada peserta sebelum menyampaikan materi. Penyaji menyampaikan materi selama 20 menit dan 3 menit terakhir dilakukan sesi tanya jawab. Lalu penyaji menampilkan video serta mendemonstrasikan cara menggosok gigi yang benar ke peserta selama 5 menit. Acara kemudian dilanjutkan dengan lomba gosok gigi, pemberian hadiah dan evaluasi materi penyuluhan yang telah disampaikan.

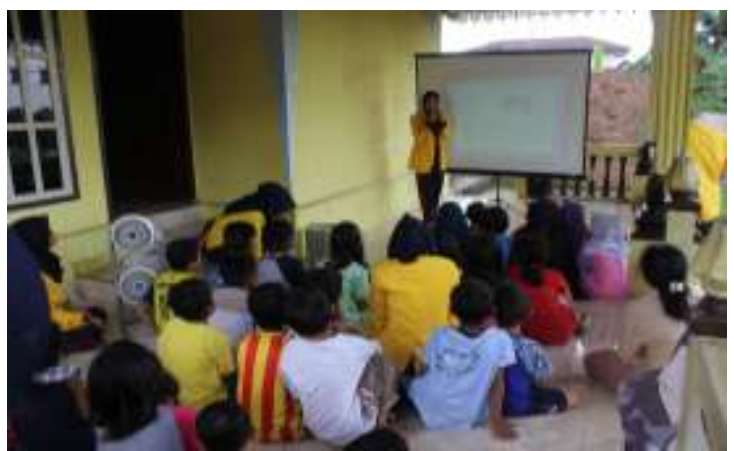

Gambar 3. Kegiatan penyuluhan

Pelaksanaan penyuluhan dilangsungkan sesuai dengan perencanaan kegiatan baik dari pembukaan, penyajian materi, tanya jawab, demonstrasi, lomba gosok gigi, kesimpulan dan penutup. Dari keseluruhan kegiatan acara penyuluhan dan lomba gosok gigi telah dilaksanakan dengan lancar dan baik, baik dari segi tempat yang kondusif, materi penyaji yang kompeten, demonstrasi dan lomba yang efektif, maupun peserta yang aktif dalam penyuluhan tersebut, Setelah dilaksanakan penyuluhan anak sekolah dapat mulai mengenal dan memahami tentang karies gigi dan anak sekolah dapat menerapkannya cara menggosok gigi yang benar dalam kehidupan sehari-hari agar mencegahnya karies gigi sedari dini.

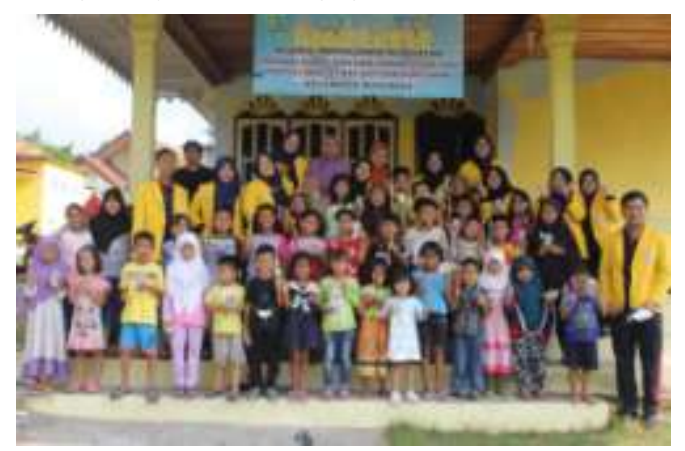

Gambar 4. Kegiatan penyuluhan 
Tabel 1. Pemenang Lomba Gosok Gigi

\begin{tabular}{|c|c|c|}
\hline No & Nama & Alasan \\
\hline 1 & $\begin{array}{l}\text { Khonsa } \\
\text { Syarifah }\end{array}$ & $\begin{array}{l}\text { Urutan dan cara } \\
\text { menggosok gigi sudah } \\
\text { benar dan tidak lupa } \\
\text { menggosok lidah yang } \\
\text { jarang dilakukan oleh } \\
\text { anak-anak lainnya. }\end{array}$ \\
\hline 2 & $\begin{array}{l}\text { Sausan } \\
\text { Sumayyah } \\
\text { Alifah }\end{array}$ & $\begin{array}{l}\text { Urutan dan cara } \\
\text { menggosok gigi sudah } \\
\text { benar tapi tidak } \\
\text { menggosok lidah }\end{array}$ \\
\hline 3 & $\begin{array}{l}\text { Fahtir } \\
\text { Wijaya }\end{array}$ & $\begin{array}{l}\text { Urutan menggosok } \\
\text { gigi masih terbalik- } \\
\text { balik tetapi cara } \\
\text { menggosok giginya } \\
\text { sudah benar dan tidak } \\
\text { menggosok lidah }\end{array}$ \\
\hline
\end{tabular}

KESIMPULAN DAN SARAN

Kegiatan dilaksanakan pada hari Kamis, tanggal 27 Juni 2019 pukul 14.25 WIB di Kediaman Ketua RT 08 Kelurahan Murni dan berakhir pada pukul 15.30 WIB. Kegiatan ini dihadiri oleh 39 anak-anak dan 7 ibu. Hasil dari kegiatan penyuluhan adalah anak-anak mampu menjelaskan kembali materi penyuluhan yang telah disampaikan dan mampu melakukan cara menggosok gigi yang benar meskipun urutannya masih ada yang salah.

Setelah dilakukan penyuluhan kesehatan tentang Karies Gigi dan Lomba Gosok Gigi di RT 08 Kelurahan Murni diharapkan anak dapat menerapkan gosok gigi yang benar pada waktu pagi dan malam hari agar dapat mencegah gigi berlubang pada anak.

\section{UCAPAN TERIMAKASIH}

Terima kasih kepada allah SWT karena berkat dan rahmat-Nya lah acara ini bisa berjalan dengan lancar, shalawat serta salam juga tidak lupa kami haturkan pada Nabi besar Muhammad, SAW, yang telah membawa kita dari zaman kegelapan ke zaman yang terang benderang seperti yang kita rasakan saat oni, terima kasih ketua dan kader RT 08 yang telah mengizinkan kami untuk melaksanakan kegiatan penyuluhan tentang karies gigi dan lomba gosok gigi, terima kasih juga untuk dosen pembimbing atas bimbingan mereka, serta masyarakat RT 08 Kelurahan Murni yang telah membantu engabdian masyrakat ini berjalan dengan sukses, kemudian untuk teman-teman kelompok Rufaidah terima kasih untuk kerja samanya, berkat semangat dan bantuan teman- teman acara ini bisa berjalan dengan lancar.

\section{DAFTAR PUSTAKA}

Arisman. 2011. Gizi dalam DAUR KEHIDUPAN. Jakarta: ECG

Irma \& Intan. 2013. Penyakit Gigi, Mulut dan THT. Yogyakarta: Nuha medika.

Kemenkes RI. 2018. Profil kesehatan Indonesia tahun 2017. Jakarta: Kemenkes RI

Kemenkes RI. 2013. Profil kesehatan Indonesia tahun 2012. Jakarta: Kemenkes RI

Sulistyowati., Septianingtias. 2017. Tindakan pencegahan karies gigi pada siswa sekolah dasar berdasarkan teori Health Belief Model. Surabaya: Jurnal Promkes. 5(1): 59-70.

Srigupta. 2011. Panduan Singkat Perawatan Gigi \& Muut. Jakarta: Prestasi Pustaka.

Susilowati \& Kuspriyanto. 2016. Gizi Dalam DAUR KEHIDUPAN. Bandung: PT Refika Aditama.

Wong. 2014. Buku Ajar Keperawatan Pediatrik. Jakarta : EGC. 